\title{
Some Notes upon the Feeding Habits of Mackerel and certain Clupeoids in the English Channel.
}

\author{
$\mathrm{By}$
}

\author{
G. E. Bullen.
}

SEveral previous authors* have shown that the food of the mackerel, when in coastal waters, is of two different kinds, and that the fish adopts two distinct methods of procuring it. In the first place it feeds by a system of filtration upon planktonic organisms, and secondly upon prey of a larger character which is hunted by sight.

The exact nature of the food taken whilst the fish is in its winter quarters has not as yet been thoroughly investigated; but the present writer, in making examination of the stomach contents of mackerel taken on the ground in March, 1907, 25 miles S.W. of Start Point, found that it consisted entirely of zoo- and phytoplankton of a nature similar to that existing in the water itself. $\dagger$ A close similarity in general character appeared to exist between the nature of these samples and otbers from fish taken in the Bristol Channel at the surface during the early part of April of the same year. $\ddagger$

It was also observed that during the three months forming the more important part of the "drifting" season in the western area, viz. April, May, and June, the fish were feeding exclusively upon plankton, and that the nature of this food gradually changed from being largely vegetable to almost wholly animal.

It was not until the middle of June that food of a larger character, but still wholly of the latter type, began to appear in stomach contents, and it is a well-known fact that at about this time every year the drift fishery in the area under consideration begins to decline, and hand-lining commences. This condition is due to the fact that the dense shoals break up, and the system of nutrition, which has hitherto been one of filtration, gives place to one of, what we may term, "selective feeding."

From the evidence before us, in the form of the plankton results for

* Vide Allen, E. J., "Rep. on the Present State of our Knowledge with Regard to the Habits and Migrations of the Mackerel," Journ. Mar. Biol. Assoc., N.S., Vol. V, p. 9.

$\dagger$ " Plankton Studies in Relation to the Western Mackerel Fishery," Journ. Mar. Biol. Assoc., N.S., Vol. XVIII., pp. 285-6.

$\ddagger$ Id. Table No. IV, Nos. 76 to 83 , and Table No. V, No. 111 . 
the stations E5 and E6 (the only two falling within the fishing area), published in the Bulletins Conseil International pour l'exploration de la $M e r$, it would appear that these several changes in the nature of the food of the mackerel, viz. from phytoplankton to general zooplankton, and from thence to zooplankton of a larger character and animal food generally, e.g. young fishes and material offered as bait, is largely, if not entirely, due to seasonal changes in the nature of the food supply itself. Yet, as it has been abundantly shown that certain planktonic organisms are of sporadic distribution, and that there is some fair evidence to show that others occur in shoals of varying extent, it remains to be seen how far the mackerel, exercising these two distinct methods of nutrition, is capable of discriminating between varying types of food during the period that it is feeding by filtration.

The question arises, to begin with, whether in adopting the one system the fish is incapable of using the other, and two important points in this connection may be considered. In the first place, the Newlyn drifters state emphatically that it is impossible to take mackerel, when closely shoaling, upon a hand-line; and secondly, it is a matter of common knowledge amongst fishermen that, when late in the summer mackerel are caught (in drift nets), when feeding heavily upon copepods, they are very liable to rapid decomposition in the region of the stomach, and that this is due to the "soft" condition of the fish themselves, and not to the increased warmth of the atmosphere. Now, with respect to this matter it may be stated that the present writer, in making examination of the stomach contents of several hundreds of mackerel taken at various times of the year, has invariably found that the walls of the stomach appeared to be contracted and thickened in cases where phytoplankton formed the bulk of the food, whereas the organ in question was distended and the walls extremely thin when zooplankton occurred. Moreover, although no careful histological comparison was made between the two types, it was found possible to distend, by means of an air-pump, to a great extent an empty stomach of the latter type without undue pressure, whereas one of the thickened type would not respond to such treatment. Again, throughout an observation extending over nearly six years upon fish in many cases from not exactly determined sources, the writer has found that, with very few exceptions, the thinning of the stomach walls is developed to the greatest extent as the western drift fishery approaches its highest point of productiveness, viz. in May and June in the case of large mackerel, and in June and July with those of smaller size, which latter, as Dr. Allen* has * op. cit., p. 25. 
pointed out, appear to be solely on feeding migration. Moreover, in all of the early spring "hooked" mackerel that the writer has examined, the walls of the stomach have been of fair thickness.

The evidence before us is certainly insufficient to warran's an assertion that a physiological change is brought about in the nature of the stomach by reason of a change of diet, but the fact remains that the writer has found it possible invariably to determine the general nature of the food contained in the stomach of a mackerel or a pilchard from an external examination of the organ itself, before it is opened.

With reference to the transitional stage from the one type of feeding to the other, the following note, received in the autumn of 1911 from Mr. Mathias Dunn, of Newlyn, is of considerable interest. This observer states :-

"I sent you yesterday some specimens of a rare Crustacean Macropsis, which has been very abundant on our coasts this summer. The mackerel have been feeding ravenously on these animals, and at times have pursued them into the harbour, where they have been so numerous as to appear like thick porridge. We have had some excellent opportunities of seeing mackerel feed, during the visit of these little creatures. They have been hunting up and down the back of the pier, like a pack of hounds, going the whole length, turning and returning again and again. They were swimming about ten to twelve feet off the pier in company with a number of scads, about twenty to thirty in each shoal, the scads in every case swimming close to the pier and the mackerel just outside. The mackerel were swimming in open order, closing in, rising and falling in graceful undulations, by which means they either drove their prey on to the surface, where there was no escape, or turned it to the centre of the shoal, where it was also promptly despatched."

Upon examination, the sample sent by Mr. Dunn was found to consist almost entirely of the Mysid Crustacean Macropsis stabberi, Van Beneden," together with a few young Herring (surface-swimming stage), and a slight number of fish ova and the Copepod Centropages typicus, Kröyer.

Unfortunately no stomach material was examined, but the foregoing observations tend to show amongst other things that the fish were feeding by sight, and were exercising discrimination in the selection of their prey. At the time when these observations were

* For the determination of this species the writer is indebted to Mr. W. M. Tattersall, M.Sc. 
made, however, viz. in July, the heavy summer drift fishery was far on the decline* and line fishing had commenced, an indication that the fish had begun to take prey of larger type.

With further reference to the feeding habits of mackerel and herring, in this instance kept in captivity at the Brighton Aquarium, the writer is indebted to Mr. E. W. Cowley, the Superintendent, for the following note.

This observer states: "The herring and mackerel are usually taken from the sea in October and November with the seine net, which is drawn on to the beach. They are then conveyed to the Aquarium in cans the size of an ordinary sanitary bin, about 20 or 30 in each can. Special care is taken to see that the cans are not overcrowded, the fish are not handled in any way, and conveyed to the tanks with the greatest possible speed. Even with these precautions we consider ourselves fortunate in saving $10 \%$ of the original catch. After they are placed in the tanks great care has to be exercised to see that the fish are in no way disturbed until they are acclimatized; but we have not found it necessary to darken the tanks.

"In the case of the herring and mackerel we find that the placing of a rock in the centre of the tank assists them considerably, unless of course a tank 120 feet long is provided.

"We feed both species upon sand-hoppers and small shrimps, alive if possible, and vary the diet from time to time with whiting cut up into small pieces. Of course great care has to be used not to overfeed them.

"The feeding is done at regular times, viz. 12 noon and 4 p.m. I have repeatedly noticed that the fish seem to know the time of feeding, for at these hours they are always on the alert. Before the food falls to the bottom of the tank it is devoured, and even when only a few shrimps or sand-hoppers are left, the fish will dart hither and thither after them.

"Usually we keep the herring and mackerel in separate tanks, but since last month (i.e. October, 1911) we have had them mixed, and I notice that they are swimming intermingled.

"During the summer months they both swim nearer to the surface than in the winter, but they never seek the bottom, being continually in motion, night and day. Otherwise there is no difference in their summer and winter movements. The temperature of the water in the tanks, which hold about 3000 gallons, is not so variable, I should think, as that of the open sea.

"Usually the mackerel live about two to three years, but we have kept herring from four to five years. No examples have ever been

*Vide "Weekly Market Reports," Fish Trades Gazette. 
measured or weighed, but certain of both species appeared to have reached sexual maturity before they died. The greatest mortality with both herring and mackerel takes place during the summer, and this may be due to the small quantity of water in the tanks, which are furnished, however, with air tubes, which continually circulate the water, day and night."

From personal observation of some mackerel which had recently been installed in one of the tanks at the Brighton Aquarium in October, 1910, the present writer would estimate the average length to be not more than 9 inches. In this connection it may be noted that Cunningham* states that the smallest ripe specimens which he had examined were $11.6 \mathrm{in}$. to $12.9 \mathrm{in}$. long.

In specimens measuring about $9 \mathrm{in}$. in length, seined at Sidmouth in 1911 towards the end of July, the writer observed no sexually mature fish, and the same condition obtained in several shoals taken by the seine at Brighton in October, 1909-10. It is fair to suppose, therefore, that the mackerel forming the subject of Mr. Cowley's observations were not sexually mature fish when placed in the tanks, and according to Cunningham $\uparrow$ about a year old.

Now, although it may be urged that observations taken upon fishes acclimatized to the abnormal conditions obtaining in an aquarium are open to question, certain points of interest present themselves when Mr. Cowley's remarks are considered. In the first place, it will be seen that mackerel and herring can exist, for a reasonable period, all the year round upon food of a type similar to that which is hunted by sight-we may almost say food of a more solid character than plankton. Secondly, although the mackerel is known to be an active swimmer and voracious feeder, its appearance as it moves leisurely round the tank at a pace of not more than two miles an hour when no disturbing influence is present, might suggest that it is either aware of the fact that the tank water does not support sufficient plankton to form a good meal, or that it is indifferent to it in view of the fact that it knows that food of a more solid nature is offered to it at regular intervals.

Returning to the opening question raised in the first paragraph, it may be suggested that here is further evidence to show that mackerel, feeding by sight upon prey of a large character, are incapable of taking nourishment by means of filtration.

Mr. Dunn's observations tend to show that the larger plankton organisms are hunted by the mackerel by sight, the fish thereby exercising a selective capability.

\footnotetext{
* Cunningham, Mark. Mar. Fishes, p. 315. † Id.
} 
To what extent this power, on the part of the fish, to discriminate between food of a wholesome character and that which is otherwisewhat we have termed "selective feeding"-is carried, may now be considered.

The writer, in a previous paper,* has remarked upon the finding of alternating layers of certain species of zooplankton, in almost pure condition, in stomach material. The same thing has been recorded in the case of the Irish mackerel. $\dagger$

The explanation of this condition originally suggested was to the effect that the fish might have been feeding first in a shoal of plankton organisms of one type and then in another, or else in different layers of water.

Prof. Ehrenbaum, of Heligoland, upon hearing of this theory, informed the writer that he had on certain occasions observed herring and mackerel, which were kept alive in tanks, showing unmistakable signs of feeding by selection upon individual copepods and other plankton organisms. $\ddagger$

Further, it may be mentioned that the present writer, in making exhaustive examination of several hundreds of stomachs of mackerel and pilchard (of the former for the purposes of the paper already cited), was never able to detect any sign of the presence of medusae. Dr. Allen, however, $\S$ in summarizing published information regarding the food of the mackerel, states: "In the first place, it feeds upon the smaller forms of the plankton, e.g. copepods and other crustaceans, larvae of crustaceans, molluses, echinoderms and worms, diatoms and even siphonophores and medusae." exceptional character is evidenced by the fact that mackerel and

* Op. cit., p. 274.

† Farran, Rep. on Sea and Inland Fisheries, Ireland, 1901, Pt. II, p. 122.

\# In reply to an enquiry respecting this statement Prof. Ehrenbaum wrote: "With reference to your enquiry, I desire to state that in the Heligoland aquarium mackerel, and at certain times also young herring, are kept alive for months, and both species have often been observed feeding in the manner described.

"Personally (and in this statement I think I have the support of many biologists), I consider that it cannot be doubted that all fish, which prey upon plankton, feed by selection. This can easily be demonstrated by an investigation of the stomach contents. Such material is never found to consist of all the various plankton components occurring within the area from whence the fish have been taken, but includes only certain species, which have been selected by the feeding fish.

"In my opinion it is a fallacy that certain fish, e.g. the mackerel, habitually swim round with an open mouth. The filtering apparatus of the gill arches is not intended to collect the plankton about to be swallowed, but serves to protect the tender gill-leaflets from possible damage caused by spurious forms of the plankton, which might occasionally be taken in the act of breathing into the mouth."

$\S$ Op. cit., p. 9 .

|| The italics have been inserted. 
pilchard drift-fishermen at Newlyn, Mevagissey and elsewhere contend that good catches are seldom made in water which "brimes" considerably. On one occasion at Mevagissey an old fisherman, on seeing several Hormiphora plumosa drop from the first net of a fleet shot for pilchard, informed the writer that he knew that there would be a poor catch, which subsequently proved to be the case. The explanation, however, which was given, was to the effect that these ctenophores, becoming caught up on the meshes, rendered the nets conspicuous by their phosphorescence.

It may be mentioned, moreover, that boats fishing further out to sea made fair catches, and it is possible that these ctenophores occurred abundantly, as is often the case, in the estuarine water flowing out of the harbour, and in the fairly still water in the immediate vicinity.

The above statements constitute our sole direct evidence of the extent to which the theory of selective feeding in mackerel and certain other drift fishes can be carried. We may therefore summarize some other points which may lend further support to the suggestion.

There is a fair amount of evidence to show that mackerel, herring, and pilchard are continually in a state of voluntary movement when engaged upon inshore migration.

With mackerel, the opinion is generally held by fishermen that once fish are known to be congregated in certain areas, unproductive fishing is due to the fact that the fish are not at the surface. The continued prevalence of N. and N.W. gales is well known to have a marked effect upon the western fishery, even at its height. The slight knowledge which we now possess respecting this fish's winter habitat* would strengthen the idea that it would naturally seek deeper layers of water, when the surface was subject to inclement conditions of atmosphere.

Mr. Cowley's statement, already cited, that mackerel and herring kept in captivity are continually in motion night and day, is quite in accordance with the views held by several intelligent fishermen, questioned on the subject by the present writer.

Moreover, the bare fact of the gradual progression shoreward of mackerel spread over a wide area at the beginning of the fishing season, resulting in a concentration of many thousands of shoals within the comparatively limited area afforded by the most productive fishing waters of May-i.e. within a 50-mile radius to the S. and S.W. of Scilly - would, to a great extent, preclude the suggestion that the fish are much affected in their inshore movements by the influence of currents.

*Vide A. Cligny, "Les pretendus migrations du maquereau." Ann. Sta. Aquicole, Boulogne-sur-mer, Nouv. Ser., Vol. I, 1905. 
In the present state of our knowledge with regard to the winter habitat of the species, it is impossible to even hazard a suggestion as to how far many of these fish, caught in the height of the season, have travelled, yet the fact remains that productive fishing is carried on nearer and nearer to land as the season continues.

It is a somewhat difficult matter to obtain precise information with regard to the rate of progression of a single shoal of drift fish. Mathias Dunn, senior, stated that this in the case of pilchards, when on migration, was about $1 \frac{1}{2}$ miles an hour.*

Some information gathered at Sidmouth in 1911, moreover, may be worthy of record. The writer was informed by two boatmen who were constantly sailing over the area under consideration, that a shoal of small mackerel was first observed off Start Point at the beginning of July. It passed too far out from Dartmouth and Exmouth to be taken in a seine, but was fished for by certain drifters within a few miles from land. The shoal finally came close inshore to the west end of the seafront at Sidmouth, where the greater part were taken in a seine, the remnant passing farther to the east. The time occupied in covering the total distance (which in a straight line is about 33 miles) was stated to be about nine days.

From a consideration of the above statements, several questions pertinent to the question of selective feeding naturally arise. In the first place, it may be suggested that when once distinct migration commences, whether it be a "spawning" or a "feeding" migration, mackerel make more or less regular daily progress towards inshore waters in the area under discussion, their movement being undeterred by the influence of currents. If this be the case, it naturally follows that were the fish to swim vigorously forward in the indiscriminate pursuit of plankton, at a pace sufficient to enhance the catching power of the mouth, their progress toward the land would be considerably more rapid than it appears to be from the slender evidence before us.

The speed, at which the small mackerel already mentioned crossed Torbay and the adjacent water, appears to have been about three to four miles a day. From observations made at Sidmouth by the present writer upon fish of this type in the years 1910-11, the food consisted for the greater part of caradid larvae with a few copepods, certainly, on the whole, organisms which might have been hunted by sight. How did these fish, therefore, take so long in covering the distance cited, unless whilst maintaining a shoal formation they were continually rounding up their prey in ceaseless movement, similar to that

\footnotetext{
* Dunn, M., "Some Habits of Picked Dogs, Herrings and Pilchards," 54th Ann.
} Rep. Royal Cornwall Polytechnic Soc., p. 5. 
described by Mr. Mathias Dunn, whilst at the same time travelling by almost imperceptible stages toward land?

Again, if it can be suggested with any degree of certainty that a plankton organism such as a caradid larva, which is considerably smaller than the mysid Macropsis, is hunted by sight-by a system of selective feeding-it is a difficult matter to determine how small an organism may be before a mackerel ceases to feed upon it with discrimination.

The present writer in a former paper* has shown that a marked correlation appears to exist between the extent of the inshore migration of mackerel during the three months constituting the more important period of the drift-fishing season in the western part of the English Channel, viz. April, May, and June, and the paucity or abundance of the zooplankton occurring in the same area.

These observations, considered collectively, would tend to show that mackerel prefer an animal to a vegetable diet, and that it is probable, with a thorough understanding of the seasonal changes occurring in the pelagic plankton of the area under consideration, it may be demonstrated that shoaling mackerel frequent, in greater numbers, those areas supporting a food supply most suited to their taste. There is considerable evidence, moreover, in support of a theory that shoals of mackerel, when entering swarms of wholesome planktonic organisms, feed ravenously upon them while they last, whilst refraining from food to a great extent when swimming in water containing, what we may suppose to be, organisms of a distasteful character. It naturally follows that in years when the coastal waters support in greater proportion food of an inferior type, the extent of the inshore migration of mackerel is largely retarded.

The question naturally arises-Can this condition be traced to the fish's own capability of discrimination in question of food? Can it also be urged that if mackerel are capable of hunting, presumably by sight, the larger forms of the zooplankton, they are also able to discern when in sufficient numbers dense shoals of the more minute forms such as the copepod Calanus finmarchicus Gunnier and others, thereby still exercising a system of selective feeding, though in this case in a more expansive sense, viz. the obtaining of large mouthfuls of suitable plankton by a selection of the type of water supporting such prey, whenever possible.

To summarize briefly the deductions which may be drawn from a consideration of the above observations, it may be stated-

$$
\text { * Op. cit., p. } 278 \text { and onward. }
$$


(a) That not only mackerel, but herring also can exist for a reasonable period of time, whilst exercising a system of nutrition by selective feeding, irrespective of season.

(b) That this system of selective feeding in mackerel and scad may extend to the larger forms of the plankton.

(c) That whilst it is impossible to determine how far the mackerel is assisted in its search for food by its power of vision, there is strong presumptive evidence to show that a capability for selective feeding, in a wider sense, may be extended to comparatively minute organisms, when they are present in sufficient numbers.

(d) And that this capability on the part of the fish to discriminate between food of a wholesome and that of a presumably unwholesome nature, would cause it to seek in greatest numbers water supporting the most suitable type of food, the extent of inshore migration thereby being largely dependent upon the planktonic condition of the coastal waters.

(e) Finally, that there is a by no means negligible amount of evidence to show that, when feeding upon the minor forms of the plankton, mackerel are incapable of assimilating other larger prey-which theory, if more fully established, would lend further support to the deduction that there is necessity for a suitable and abundant supply of plankton in the inshore waters before the shoals are induced to approach the land in sufficient numbers to form a profitable fishery.

In the preparation of this paper the writer's thanks are due to Mr. Mathias Dunn and Mr. E. W. Cowley for their valuable observations, also to Dr. E. J. Allen for much assistance and advice. 